\title{
A justiça e o direito fundamental ao meio ambiente
}

\author{
César Augusto Cichelero" \\ Paulo Cesar Nodari" \\ Cleide Calgaro ${ }^{* * *}$
}

\begin{abstract}
Recibido: 11 de dezembro de 2017 • Aprobado: 18 de março de 2018
https://doi.org/10.22395/ojum.v17n34a8
\end{abstract}

\begin{abstract}
RESUMO
O objetivo deste trabalho é analisar a justiça ambiental e o direito fundamental ao meio ambiente como forma de garantir e realizar o mínimo existencial à luz da concepção de justiça de John Rawls. A partir de uma abordagem analítica, desenvolve-se a tese de que o direito fundamental ao meio ambiente se agrega ao rol de direitos fundamentais, argumentando que o mínimo existencial ecológico pode ser sustentado como corolário da dignidade da pessoa humana. Parte-se da teoria rawlsiana de justiça para fundamentar a tutela ao meio ambiente, objeto de proteção e tutela jurídica, em virtude de ser a condição da própria existência e da efetivação dos demais direitos humanos. Por fim, sustenta-se que a proteção do mínimo existencial ecológico para todos os indivíduos estaria em conformidade com os pressupostos de um Estado Socioambiental e, em última análise, que se trata de uma das formas da realização de uma teoria da justiça.
\end{abstract}

Palavras-chave: Justiça ambiental; John Rawls; mínimo existencial; ética; meio ambiente.

- Artigo de investigação desenvolvido no âmbito do grupo de pesquisa Metamorfose Jurídica, da Universidade de Caxias do Sul, Caxias do Sul, Brasil, e do projeto "Ética socioambiental e o constitucionalismo latino-americano para a construção de uma democracia socioecológica na sociedade consumocentrista", financiado pela Fundação de Amparo à Pesquisa do Estado do Rio Grande do Sul.

" Graduado em Direito pela Universidade de Caxias do Sul, Caxias do Sul, Brasil. Mestre em Direito pela Universidade de Caxias do Sul, Caxias do Sul, Brasil. Bolsista da Coordenação de Aperfeiçoamento de Pessoal de Nível Superior. E-mail: cesar.cichelero@gmail.com

... Graduado em Filosofia pela Universidade de Caxias do Sul, Caxias do Sul, Brasil. Graduado em Teologia pela Pontifícia Universidade Católica do Rio Grande do Sul, Porto Alegre, Brasil. Mestre em Filosofia pela Universidade Federal de Minas Gerais, Belo Horizonte, Brasil. Doutor em Filosofia pela Pontifícia Universidade Católica do Rio Grande do Sul, Porto Alegre, Brasil. Pós-Doutor pela Universidade de Bonn, Alemanha. Professor adjunto II na Universidade de Caxias do Sul, Brasil. E-mail: paulocesarnodari@hotmail.com

.... Graduada em Direito pela Universidade de Caxias do Sul, Caxias do Sul, Brasil. Mestra em Direito e em Filosofia pela Universidade de Caxias do Sul, Caxias do Sul, Brasil. Doutora em Ciências Sociais pela Universidade do Vale do Rio dos Sinos, São Leopoldo, Brasil. Pós-doutora em Filosofia e em Direito pela Pontifícia Universidade Católica do Rio Grande do Sul, Porto Alegre, Brasil. Doutoranda em Filosofia na Pontifícia Universidade Católica do Rio Grande do Sul. Professora, pesquisadora e vice-líder do grupo de pesquisa Metamorfose Jurídica. http://lattes.cnpq.br/8547639191475261. E-mail: ccalgarol@hotmail.com 


\section{Justice and the fundamental right to the environment}

\section{ABSTRACT}

The objective of the text is to analyze environmental justice and the fundamental right to the environment as a way of guaranteeing and realizing the existential minimum in the light of John Rawls' conception of justice. From an analytical approach, the thesis is developed that the fundamental right to the environment is added to the group of fundamental rights, arguing that the ecological existential minimum can be sustained as a corollary of the dignity of the human person. We start from the Rawlsian theory of justice to base the protection to the environment, object of protection and juridical tutelage, because it is the condition of the own existence and the realization of the other human rights. Finally, it is argued that the protection of the ecological existential minimum for all individuals would be in conformity with the premises of a socio-environmental State and, in the final analysis, that it is one of the forms of realization of a theory of justice.

Keywords: environmental justice; John Rawls; existential minimum; ethics; environment.

\section{Justicia y derecho fundamental al medio ambiente}

\section{RESUMEN}

El objetivo del texto es analizar la justicia ambiental y el derecho fundamental al medio ambiente como forma de garantizar y realizar el mínimo existencial a la luz de la concepción de justicia de John Rawls. Desde un enfoque analítico, se desarrolla la tesis de que el derecho fundamental al medio ambiente se agrega al grupo de derechos fundamentales, argumentando que el mínimo existencial ecológico puede sostenerse como corolario de la dignidad de la persona humana. Se parte de la teoría rawlsiana de justicia para fundamentar la tutela al medio ambiente, objeto de protección y tutela jurídica, debido a que es la condición de la propia existencia y la realización de los demás derechos humanos. Porfin, se sostiene que la protección del mínimo existencial ecológico para todos los individuos estaría en conformidad con las premisas de un Estado socioambiental y, en último análisis, que se trata de una de las formas de realización de una teoría de la justicia.

Palabras clave: Justicia ambiental; John Rawls; mínimo existencial; ética; medio ambiente. 


\section{INTRODUCÃO}

A crise ambiental se tornou mais evidente na década de 1960. Iniciou-se, a partir de então, a reflexão acerca da irracionalidade ecológica dos padrões dominantes de produção e de consumo, e marcou os limites do crescimento econômico. A atual degradação ambiental se manifesta como sintoma de uma crise da civilização ocidental, caracterizada pelo modelo de modernidade regido pelo predomínio do desenvolvimento da razão tecnológica sobre a organização da natureza. Além da crise ambiental, percebe-se o aumento da difusão da temática ambientalista nas últimas décadas, desde um aumento expressivo dos estudos acerca do meio ambiente na academia, maior produção de reportagens na mídia, aumento da preocupação do meio artístico, mas, principalmente, denota-se uma maior percepção dos sujeitos quanto às mudanças do meio ambiente - aquecimento global, extinção de espécies, aumento dos eventos extremos etc. Essa crise ambiental exposta por tantos juristas e ambientalistas tem como causa última a paradoxal relação entre os homens e do homem com a natureza. Trata-se, no fim de contas, da crise antropocêntrica, ou seja, da crise antropológica e da crise ecológica.

Permeando esse contexto de crise ambiental, o discurso acerca da justiça ambiental vem se expandindo substancialmente na contemporaneidade, tendo se tornado um ponto de essencial e contínua desenvoltura teórica. O escopo do que a justiça ambiental trabalha se ampliou de uma forma que vai muito além de suas previsões iniciais, que estavam ligadas à distribuição de riscos ambientais. Nesse contexto de abrangência e amplitude da temática, escolheu-se tratar neste texto da problemática da justiça ambiental e sua relação com a teoria de justiça de John Rawls. Para isso, busca-se demonstrar que a justiça ambiental teve um papel importante ao desafiar as noções de meio ambiente e as possibilidades de justiça social. Nesse sentido, adota-se o procedimento de revisão da literatura, a partir de pesquisa bibliográfica e documental, essencialmente doutrinária, mas com eventuais contribuições da jurisprudência e da legislação.

Os direitos humanos fundamentais estão conectados com a justiça ambiental pelas graves injustiças ambientais que implicam violação desses direitos. Essa relação se torna ainda mais próxima quando se lembra do reconhecimento do meio ambiente ecologicamente equilibrado como um direito humano fundamental pela Constituição brasileira de 1988. Além da norma brasileira, a Declaração da Conferência das Nações Unidas sobre o Meio Ambiente Humano (Declaração de Estocolmo) em 1972 prevê que o meio ambiente natural e o artificial são essenciais para o bem-estar e para o gozo dos demais direitos humanos fundamentais, que incluem o direito à própria vida. Existe uma óbvia relação entre a preservação do ambiente planetário, os direitos humanos e a justiça ambiental que decorre da seguinte constatação: "o equilíbrio ecológico do planeta Terra é condição essencial para que não sejam violados os direitos humanos, 
provocando, assim, injustiças ambientais" (Rammê, 2012, p. 110).

Desse modo, neste artigo, em primeiro lugar, trata-se de discutir as origens da justiça ambiental e a teoria de justiça de Rawls. E, em um segundo momento, busca-se explorar as relações desses dois conceitos com a ideia de um mínimo existencial capaz de garantir a realização dos direitos fundamentais, especialmente o direito ao meio ambiente ecologicamente equilibrado, com uma base na teoria rawlsiana. Por fim, espera-se conseguir demarcar os aspectos conceituais do tema aqui referenciado, sua justificação normativa e trazer à tona algumas questões problemáticas acerca de sua efetivação.

\section{JUSTICA AMBIENTAL E A TEORIA DE JOHN RAWLS}

O termo "justiça ambiental" tem origem nos movimentos sociais norte-americanos que, a partir da década de 1960, passaram a reivindicar direitos civis aos grupos afrodescendentes. Ao mesmo tempo em que exigiam a diminuição da desigualdade em outras áreas, eles protestavam contra a sua exposição aos rejeitos tóxicos provenientes das indústrias. Como expõe Martínez-Alier (2007, p. 35), a "justiça ambiental é um movimento social organizado contra casos locais de 'racismo ambiental', possuindo fortes vínculos com o movimento dos direitos civis de Martin Luther King nos anos 1960". Assim, em um primeiro momento, a justiça ambiental se liga ao racismo ambiental, ou seja, à distribuição desproporcional de resíduos tóxicos junto às minorias so- ciais. É possível compreender o racismo ambiental como a discriminação racial presente nas políticas ambientais. Em outras palavras, é uma discriminação racial deliberada na escolha de certas comunidades para depositar rejeitos e instalar indústrias poluidoras, tudo realizado sob o aval da lei. Além disso, a discriminação racial é a exclusão de grupos raciais dos principais grupos ambientalistas, dos comitês de políticas públicas ambientais e das instituições regulamentadoras.

Deve-se fazer menção que aqueles que exigem justiça ambiental não estão fazendo conexão com aqueles que pregam a utilização sustentável e eficiente dos recursos naturais, ou aqueles outros que entendem que as externalidades ambientais deveriam ser compensadas; justiça ambiental trata de discriminação em virtude de pertencer a uma minoria social e da decorrente repercussão ambiental. Ou seja, quem apenas prega a sustentabilidade não está preocupado, a priori, com certas discrepâncias sociais que dificultam o acesso aos bens ambientais e aumentam os riscos ambientais.

Assim, é possível afirmar que o movimento por justiça ambiental surgiu vinculado a dois outros movimentos sociais: o movimento contra a contaminação tóxica e o contra o racismo ambiental. Várias são as causas que podem ser apontadas para a produção de injustiça ambiental no mundo moderno, tais como o mercado competitivo, a política distante da sociedade, a falta de transparência e os discursos que neutralizam um discurso crítico. O mercado acaba criando uma segregação 
espacial, pois aloca, nas mesmas áreas, grupos sociais de baixo poder aquisitivo e os riscos ambientais; já as políticas, quando existem, são mais rígidas para as camadas sociais mais baixas; a mídia, controlada pelas grandes empresas, evita que os riscos se tornem públicos e se debatam; por fim, as corporações criam retóricas para conquistar a simpatia dos indivíduos.

Com o passar dos anos, o movimento por justiça ambiental aderiu a novos objetivos e novas fronteiras, encontrando adeptos mundo afora; assim, ganha contornos mais amplos em relação às suas antigas delimitações. "Atualmente, o movimento por justiça ambiental abarca todos os conflitos socioambientais cujos riscos sejam suportados de forma desproporcional sobre populações socialmente vulneráveis ou mesmo os países ditos de 'Terceiro Mundo'" (Rammê, 2012, p. 23). Para uma melhor conceituação, recorre-se a Leff (2009, p. 69), que afirma que o movimento por justiça ambiental é de resistência cultural, de estilo de vida e de defesa do meio ambiente, além de ser contra as externalidades de uma economia cada vez mais globalizada. Segundo Martínez-Alier (2007), a justiça ambiental procura uma equanimidade em relação aos conflitos ecológicos distributivos.

A consideração da justiça ambiental como uma demanda social é reveladora de um cenário complexo, visto que as discussões sobre a necessidade de proteção da natureza e de manutenção dos direitos humanos fundamentais se inserem no contexto da chamada crise ambiental, colocada em um campo de tensão na modernidade. As reivindicações por justiça ambiental, portanto, caracterizam-se pela percepção de que existe uma má distribuição dos bens e dos riscos ambientais nas sociedades contemporâneas, afetando e até mesmo violando direitos das parcelas mais vulneráveis da população. Além disso, é necessário pontuar que a justiça ambiental não se confunde com a justiça ecológica; esta busca corrigir as formas de atuação humana que levam à degradação da natureza. Por outro lado, a justiça ambiental pretende superar as desigualdades impostas pelo processo de produção capitalista, reveladas pela concentração das consequências da degradação da natureza em grupos sociais economicamente frágeis; desse modo, a superação se daria pela instituição de mecanismos de distribuição dos riscos e dos bens ambientais (Baggio, 2008).

Com o intuito de melhor fundamentar uma proposta de justiça ambiental, recorre-se à teoria de John Rawls. A justiça para o filósofo político norte-americano, que está assentada na tradição liberal, baseia-se em uma ética deontológica de origem kantiana, segundo a qual o indivíduo, pela razão prática, escolhe livremente seguir a lei moral (Lumertz e Vieira, 2012). Para Rawls, as instituições de uma sociedade precisam estar fundamentadas moralmente de tal forma que possam cumprir o papel de garantir soluções democráticas, sendo que o principal objetivo de sua obra é formular uma concepção de justiça que forneça uma alternativa ao utilitarismo até então predominante. Além disso, é necessário pontuar que 
Rawls adota a prioridade do justo sobre o bem, fornecendo à sua teoria um caráter deontológico, e não teleológico.

Rawls defende a utilização de critérios para a definição do justo, visto que a disputa sobre o conteúdo da justiça acontece em casos concretos, cada um dos interessados tem uma posição inicial parcial. Para resolver esse problema, Rawls apresenta o conceito de justo por equidade, que coloca a discussão em termos contratuais; portanto, a escolha de princípios morais não pode estar subordinada a situações particulares. Assim, é necessária uma situação hipotética, na qual os sujeitos se encontram sob um "véu de ignorância". Nessa posição original hipotética, as partes considerariam de forma imparcial os pontos de vista de todos e os demais estariam direcionados à busca de bens primários, ou seja, bens básicos indispensáveis, que podem ser naturais ou sociais (Albuquerque, 2015). Vale lembrar que Rawls trabalha dois tipos de bens primários: os sociais (que ele aprofunda em sua teoria) e os naturais. A posição original é a situação mais adequada por garantir a liberdade de reflexão racional pelo sujeito e por estabelecer a possibilidade de igualdades entre todos. Segundo Rawls:

Parece razoável supor que as partes na posição original são iguais. Isto é, todas têm os mesmos direitos no processo da escolha dos princípios; cada uma pode fazer propostas, apresentar razões para a sua aceitação e assim por diante. Naturalmente a finalidade dessas condições é representar a igualdade entre os seres huma- nos como pessoas éticas, como criaturas que têm uma concepção do seu próprio bem e que são capazes de ter um senso de justiça. (Rawls, 2008, p. 23)

Com a utilização desse cenário hipotético, Rawls acredita que não existem motivos para que os sujeitos ajam de forma mal-intencionada para com os demais, visto que eles agem por regras racionais de escolhas. Desse modo, é possível acreditar em um consenso obtido nessa posição original, o que levaria a dois princípios de justiça.

\begin{abstract}
Primeiro: cada pessoa deve ter um direito igual ao mais abrangente sistema de liberdades básicas iguais que seja compatível com um sistema semelhante de liberdades para as outras. Segundo: as desigualdades sociais e econômicas devem ser ordenadas de tal modo que sejam ao mesmo tempo (a) consideradas como vantajosas para todos dentro dos limites do razoável, e (b) vinculadas a posições e cargos acessíveis a todos. (Rawls, 2008, p. 73)
\end{abstract}

O princípio da igualdade trata dos critérios de acesso às oportunidades dos indivíduos ante os bens sociais. A ideia aqui é neutralizar ou diminuir a influência dos fatores arbitrários para evitar que as expectativas de sujeitos possuidores das mesmas habilidades sejam afetadas pela sua classe social. Rawls entende que a maneira pela qual a natureza distribui as vantagens não é justa ou injusta; a natureza é uma roleta natural, em que alguns aleatoriamente acabam por ser mais privilegiados em determinados bens que 
outros. Contudo, ao contrário da natureza, o sistema de distribuição de recursos pode ser julgado como justo ou injusto. $\mathrm{O}$ problema não é redistribuir recursos que foram desigualmente distribuídos, mas, primeiro, mudar as instituições que governam a distribuição de tais recursos, ou seja, modificar os critérios de distribuição. Dessa maneira, a partir do modo como os bens são concedidos pela natureza, as instituições devem fazer a distribuição dos recursos existentes (Rigo, 2015).

O segundo princípio faz menção à necessidade de todos agirem cooperativamente para que seja possível usufruir dos bens. O princípio da diferença significa a superação de uma ideia de justiça meramente distributiva; em outras palavras, para esse princípio, o benefício maior dos mais privilegiados só é possível se os menos favorecidos sejam também beneficiados. Ou seja, só é possível agir de forma desigual na distribuição de recursos, se isso fosse beneficiar os menos favorecidos, sem, contudo, subtrair os seus recursos (Rigo, 2015). Assim, o princípio da diferença inova em fazer das desigualdades um subcaso das igualdades. Visto que todos possuem os mesmos direitos e deveres, essas desigualdades são justas e equitativas quando acarretam no benefício de todos. Desse modo, justas são as sociedades e as instituições que sigam o princípio da diferença, pois elas visam corrigir a distribuição desigual natural, sem acarretar limitações aos beneficiados naturalmente (Lumertz e Vieira, 2012).

A teoria Rawls trata, então, de quatro etapas na institucionalização da justiça e na definição das normas para a distribuição dos bens públicos: (1) contrato político de justiça, formado pela posição original; (2) estabelecimento desse contrato, em uma Constituição; (3) aprovação de leis complementares à Constituição; (4) aplicação das leis pelo judiciário. Nesse sentido, as políticas ambientais devem ser estabelecidas pelo poder legislativo. Segundo Felipe (2006), Rawls entende que é preciso regulamentar o uso dos recursos naturais; esta é a única forma de controlar pública e institucionalmente o impacto negativo da exploração do ambiente.

\section{MÍNIMO EXISTENCIAL COMO JUSTICA AMBIENTAL E RESPEITO AOS DIREITOS FUNDAMENTAIS}

A Constituição Federal Brasileira de 1988, ao instituir o Estado Democrático de Direito, consagrou, em seu artigo $1^{\circ}$, inciso III, como fundamento a dignidade da pessoa humana. Entende-se por dignidade da pessoa humana a qualidade intrínseca e distintiva reconhecida em cada indivíduo que o faz merecedor de respeito e consideração por parte do Estado e da sociedade.
O reconhecimento e a promoção da dignidade é uma conquista da história, mas ao mesmo tempo é uma construção da razão. Indica um dever ser. É normativa. É uma qualidade intrínseca do ser pessoa. Define o homem como fim em si mesmo, para usar uma expres- são kantiana. E isso, obviamente, não depende de desenvolvimento histórico. Mencioná-la no prelo e/ ou nos artigos iniciais e basilares 
de uma Constituição significa estabelecer a inviolabilidade do ser humano como pressuposto de toda a estrutura jurídica e social, reconhecendo-o como sujeito do direito, isto é, como portador de direitos e deveres. Estabelecer a dignidade da pessoa humana como fundamento de uma Constituição, tal como o faz a brasileira, significa dizer que ela se constitui no referencial teórico e base de sustentação de toda a estrutura jurídica e social. Ela é um princípio sobre o qual se ergue a ordem constitucional. Significa, portanto, que não pode ser violada e que, ao mesmo tempo, deve ser protegida e promovida. (Weber, 2013, p. 198-199)

Decorre dessa afirmação um feixe de direitos e deveres fundamentais que asseguram à pessoa proteção contra todo e qualquer ato degradante e desumano, e garantia de suas condições existenciais mínimas para uma vida saudável, além de promover sua participação ativa e corresponsável nos destinos da própria existência e da vida em comunidade (Sarlet, 2009). Para Fensterseifer (2008), a dignidade da pessoa humana é a matriz axiológica do ordenamento jurídico, o princípio de maior hierarquia da nossa Constituição e a pedra basilar da edificação constitucional do Estado (social, democrático e ambiental) ${ }^{1}$.

\footnotetext{
"De qualquer modo não é difícil perceber que, com algum esforço argumentativo, tudo que consta no texto constitucional pode - ao menos de forma indireta - ser reconduzido ao valor da dignidade da pessoa humana. Em realidade, a grande maioria dos direitos e garantias fundamentais, ainda que de modo e intensidade variáveis, têm a sua fonte ética na dignidade da pessoa [...]". (Almeida, 2009, p. 68)
}

Além disso, "como um valor fundamental que é também um princípio constitucional, a dignidade humana funciona tanto como justificação moral quanto como fundamento jurídico-normativo dos direitos fundamentais" (Barroso e Mello, 2015, p. 43). Assim, os direitos humanos devem ser interpretados tendo como parâmetro o valor da dignidade da pessoa humana, o que impõe a sua máxima realização e observância plena. Em outras palavras, é exatamente pelo fato de os direitos humanos explicitarem o conteúdo axiológico da noção de dignidade da pessoa humana que são considerados fundamentais, devendo ser realizados na maior medida possível.

A partir de uma compreensão necessariamente multidimensional e não reducionista da dignidade da pessoa humana, defende-se o reconhecimento de uma dimensão ecológica da dignidade humana. Esta não deve ser restringida a uma dimensão puramente biológica ou física, afinal contempla a qualidade de vida como um todo, inclusive do ambiente em que a vida humana se desenvolve, de modo a assegurar um padrão de qualidade e segurança ambiental mais amplo (Sarlet e Fenstersiefer, 2014a). É preciso destacar que a dimensão ecológica da dignidade humana amplia o conteúdo da dignidade, pois visa garantir um padrão de qualidade, equilíbrio e segurança ambiental (Fensterseifer, 2008).

Em razão de ser a dignidade humana o pilar-mestre ou a pedra fundamental de toda a edificação jurídico-constitucional contemporânea, qualquer modificação 
conceitual nela provocada acaba por repercutir e projetar-se para todo o sistema jurídico, principalmente no que tange aos direitos fundamentais e à própria conformação do Estado de Direito. (Sarlet e Fensterseifer, 2007, p. 75)

A qualidade e a segurança ambiental se tornam elementos integrantes do conteúdo normativo da dignidade da pessoa humana, e são necessárias para o desenvolvimento pleno dos sujeitos. Desse modo, não é possível conceber uma vida digna sem um ambiente saudável e equilibrado, em especial devido à densidade axiológica do artigo 225 da Constituição Federal. Isto é, na esfera jurídica contemporânea, com o crescimento das discussões ambientais, o paradigma antropocêntrico é superado e é aberto espaço para os diferentes conceitos de antropocentrismo alargado, antropocentrismo ecológico, ecocentrismo, biocentrismo etc.

A existência do ser humano com dignidade depende, por óbvio, da existência deste planeta. Discutem-se, portanto, os limites do antropocentrismo das dimensões individual e social da dignidade humana, ante uma nova dimensão: a ecológica. Claro que existem controvérsias sobre a necessidade da existência de uma dimensão ecológica da dignidade humana, todavia tais discussões também aconteceram quando foi defendida a existência da dimensão social da dignidade humana. Reconhecer essa dimensão é essencial à própria existência da dignidade humana, visto que não é possível a existência da vida humana sem a existência da vida em geral.
Isso se deve ao fato de que a Constituição transformou a visão que se tinha do bem ambiental que, até então, era um bem público. Após 1988, ele passa a ter natureza difusa e surge, na nova ordem constitucional, com três características. A primeira diz respeito a ser um bem de uso comum do povo; como segunda característica, é um bem essencial à sadia qualidade de vida, o que importa à satisfação do fundamento do Estado Socioambiental brasileiro, ou seja, a dignidade da pessoa humana; por último, de ser um bem intergeracional, que deve ser garantido e protegido para as gerações presente e futura (Miranda e Calça, 2014).

Dessa forma, o processo histórico de conquista dos direitos fundamentais oportunizou que a proteção ambiental fosse inserida nesse seleto rol, o que ocasionou que o conteúdo do mínimo existencial, que já contemplava uma dimensão social, devesse se modificar para compreender, também, uma dimensão ecológica, que assumisse características socioambientais. Pois, no caminho de realizar as normas expressas no artigo 225 da Constituição Federal, observa-se que a promoção da sadia qualidade de vida só é possível dentro de padrões mínimos estabelecidos constitucionalmente para o desenvolvimento pleno da personalidade humana, de um ambiente com qualidade e segurança.

Assim como outrora os direitos liberais e os direitos sociais formatavam o conteúdo da dignidade humana, hoje também os direitos de solidariedade, como é o caso especialmente do direito ao ambiente, passam a 
conformar o conteúdo da dignidade humana, ampliando o seu âmbito de proteção. (Sarlet e Fensterseifer, 2007, p. 74)

Diante disso, extrai-se a importância da dignidade da pessoa humana como fundamento do Estado Socioambiental de Direito; este pode ser compreendido como produto das novas reivindicações fundamentais do ser humano e particularizado pela ênfase que confere à proteção do meio ambiente (Leite e Ayala, 2014).

Segundo Canotilho (1998), a qualificação de um Estado como Estado Socioambiental aponta em - pelo menos — duas dimensões jurídico-políticas. Primeiramente, observa-se a obrigação do Estado, em cooperação com outros Estados e cidadãos ou grupos da sociedade civil, de promover políticas públicas (econômicas, educativas, de ordenamento) pautadas pelas exigências da sustentabilidade ecológica; além disso, a segunda dimensão aponta para o dever da adoção de comportamentos públicos e privados amigáveis com o ambiente, dando expressão concreta à assunção da responsabilidade dos poderes públicos perante as gerações futuras. Considerando o exposto, e seguindo Sarlet e Fensterseifer (2014b), considera-se possível agregar um terceiro eixo às duas dimensões propostas por Canotilho, notadamente o dever do Estado de promover políticas socioambientais que assegurem, igualmente de modo sustentável (mas progressivo), a toda a sociedade as condições para uma vida digna, na perspectiva da garantia de um mínimo existencial não apenas vital, mas também socioambiental.
Em vista do conteúdo e da força normativa do princípio (e também valor) jurídico da dignidade da pessoa humana, decorrem dele direitos tanto de natureza defensiva (negativa) como prestacional (positiva). Um exemplo seria a garantia constitucional do mínimo existencial, a garantia das prestações materiais mínimas necessárias a uma vida em patamares dignos (Fensterseifer, 2008). O princípio da dignidade da pessoa humana se relaciona com o núcleo do mínimo existencial. Para uma realização plena da dignidade humana, é necessária a compreensão de seu caráter ecológico; afinal, uma qualidade mínima ambiental é necessária para a pessoa humana; nesse sentido, frisa-se que o meio ambiente equilibrado constitui elemento dessa dignidade. "Então resta uma pergunta: será que devemos reduzir o mínimo existencial ao direito de subsistir?" (Garcia, 2013, p. 34).

O conteúdo do mínimo existencial não pode ser confundido com a ideia de "mínimo vital", pois este diz respeito à garantia da vida humana, sem necessariamente abranger as condições para uma sobrevivência física em condições dignas, portanto de uma vida com certa qualidade. Como apontam os autores, não deixar alguém sucumbir à fome, certamente, é o primeiro passo para garantir um mínimo existencial, contudo não é o suficiente para a garantia de uma existência digna, ainda mais em vista dos novos riscos existenciais postos pela crise ambiental (Sarlet e Fensterseifer, 2010).

No Brasil, ainda que inexista uma previsão taxativa e expressa no texto constitucio- 
nal sobre o direito e a garantia a um mínimo existencial, é possível fazer menção ao amplo rol de direitos sociais que devem ser prestados por parte do Estado. Assim, o que importa é a percepção de que o di reito fundamental ao mínimo existencial independe de expressa previsão constitucional para poder ser reconhecido, visto que decorre diretamente da proteção da vida e da dignidade da pessoa humana ${ }^{2}$. Nesse contexto, há que enfatizar que o mínimo existencial —compreendido como todo o conjunto de prestações materiais indispensáveis para assegurar a cada sujeito uma vida com dignidade e, portanto, saudável — tem sido identificado como o núcleo essencial dos direitos fundamentais sociais, núcleo este blindado contra toda e qualquer intervenção por parte do Estado e da sociedade. (Sarlet, 2013).

O reconhecimento do direito ao ambiente ecologicamente equilibrado como um direito fundamental, dessa maneira, incorpora novos elementos ao conteúdo do mínimo existencial social. Ou seja, pode-se falar agora em uma dimensão ecológica do direito ao mínimo existencial, que, em virtude da necessária agregação com a agenda de proteção e promoção de

2 Dentro das outras justificativas que se poderiam invocar, também para efeitos do reconhecimento de uma garantia constitucional do mínimo existencial socioambiental, assume relevância a noção do dever de respeito e consideração, por parte da sociedade e do Estado, pela vida de cada indivíduo, que, de acordo com o imperativo categórico formulado por Kant, deve ser sempre tomada como um fim em si mesmo, em sintonia com a dignidade (e sua dimensão ecológica) inerente atribuída e reconhecida a cada ser humano (Sarlet e Fensterseifer, 2014a, p. 133). uma existência digna em termos sociais (portanto, não restrita a um mínimo vital), há de ser designada pelo rótulo de um mínimo existencial socioambiental, coerente, aliás, com o projeto jurídico, político, social, econômico e cultural do Estado Socioambiental de Direito (Sarlet e Fensterseifer, 2010).

A ideia de mínimo existencial compreende o conjunto de prestações materiais que garantem aos sujeitos uma vida com dignidade, que somente pode ser uma vida em um ambiente saudável, por padrões qualitativos mínimos. A dignidade da pessoa humana é o norte jurídico para definir o mínimo existencial, por isso que este visa proteger mais do que a mera sobrevivência física (Sarlet e Fensterseifer, 2014a). Um mínimo ecológico de existência tem a ver, consequentemente, com a proteção de uma esfera existencial ambiental que deve ser mantida e reproduzida. Deve-se considerar que o mínimo não está sujeito a iniciativas revisoras próprias do exercício das prerrogativas democráticas conferidas à função legislativa. Logo, aqui, compreende-se como a concepção da ideia de mínimo existencial ecológico estabelece relações com o princípio da proibição de retrocesso, pois uma dimensão ecológica existencial deve ser protegida e garantida contra iniciativas que possam, em alguma medida, representar ameaça a padrões ecológicos elementares da vida e da dignidade humana (Ayala, 2010). Diante disso,

há como extrair, ainda, outra constatação de relevo também para os desenvolvimentos subsequentes, 
qual seja, a impossibilidade de se estabelecer, de forma apriorística e, acima de tudo, de modo taxativo, um elenco dos elementos nucleares do mínimo existencial, no sentido de um rol fechado de posições subjetivas (direitos subjetivos), negativos e positivos correspondentes ao mínimo existencial, o que evidentemente não afasta a possibilidade de se inventariar todo um conjunto de conquistas já sedimentadas e que, em princípio e sem excluir outras possibilidades, servem como uma espécie de roteiro a guiar o intérprete e, de modo geral, os órgãos vinculados à concretização dessa garantia do mínimo existencial. (Sarlet, 2013, p. 39)

Somado a isso, percebe-se a preocupação doutrinária de se conceituar e definir, em termos normativos, um padrão mínimo ecológico para a concretização da dignidade humana. Tal preocupação se dá em razão de que a qualidade ambiental retém uma importância essencial para o desenvolvimento da vida humana em toda a sua potencialidade. Diante dessa compreensão, das necessidades humanas básicas, na perspectiva das gerações presente e futura, coloca-se a reflexão acerca da exigência de um patamar mínimo de qualidade ambiental, sem o qual a dignidade humana estaria sendo violada em seu núcleo essencial.

O âmbito de proteção do direito à vida, ante a presença dos riscos ambientais contemporâneos, para atender ao padrão de dignidade assegurado constitucionalmente, deve ser ampliado no sentido de abarcar a dimensão ambiental em sua esfera normativa (Sarlet e Fensterseifer, 2010). Assim, da mesma maneira que são imprescindíveis determinadas condições materiais para assegurar adequados níveis de bem-estar social, sem as quais o pleno desenvolvimento humano e, até mesmo, a sua inserção política é inviabilizado, também, na dimensão ambiental, é possível falar em um conjunto mínimo de condições materiais em termos de qualidade ambiental, uma vez que, sem ele, o desenvolvimento da vida humana se encontra prejudicado e em desconformidade com a imposição constitucional que delega ao Estado o dever de tutelar a vida e a dignidade humana contra essas ameaças existenciais.

Além de que, sem o acesso às condições existenciais mínimas, nas quais se inclui necessariamente um padrão mínimo de qualidade ambiental, não há como falar em liberdade real, muito menos em um modo de vida digno. Afinal, a garantia do mínimo existencial ecológico (como direito fundamental) se torna, sob certa perspectiva, uma condição de possibilidade do próprio exercício dos outros direitos fundamentais (Sarlet e Fensterseifer, 2010).

Em sequência, pode-se argumentar que a proteção ambiental possui grande relação com a garantia e proteção dos demais direitos sociais, já que o gozo destes últimos somente é possível dentro de condições ambientais favoráveis. A preservação de um patamar mínimo de qualidade ambiental deve ser atribuída, tanto na forma de deveres de proteção do Estado como na forma de deveres fun- 
damentais dos atores privados, à geração humana presente, de modo a preservar as bases naturais mínimas para o desenvolvimento - e mesmo a possibilidade — da vida das gerações futuras. Desse modo, o que se apresenta é a imposição da conjugação dos direitos sociais e dos direitos ambientais para efeitos de identificação dos patamares necessários de tutela da dignidade humana, no sentido do reconhecimento de um direito ao mínimo existencial socioambiental, precisamente pelo fato de tal direito abarcar o desenvolvimento de todo o potencial da vida humana até a sua própria sobrevivência como espécie, a fim de proteger o homem contra a sua própria ação predatória (Sarlet e Fensterseifer, 2010).

Nessa mesma linha, está a teoria de John Rawls. Esse filósofo político americano deixa bem claro em seus escritos que viver não é apenas sobreviver, pois uma concepção de justiça deve ter como base fundamental a prescrição de condições mínimas para que a pessoa possa se desenvolver, ou não terá uma vida digna e muito menos poderá atuar como cidadão. Nesse ponto, busca-se aproximar o princípio da dignidade da pessoa humana com a ideia de cidadania. A dignidade da pessoa humana, assim como a cidadania, reúne um conjunto de direitos e deveres fundamentais. Ela está ligada a uma comunidade política, dentro da qual os direitos podem ser exercidos, reconhecidos e protegidos. Além disso, cidadania e dignidade exigem a garantia de condições materiais suficientes para que seja possível seu exercício, de modo a promover a participação ativa e responsável dos indi- víduos na sociedade. Portanto, dignidade humana e cidadania não se confundem, interconectam-se.

Visto que a garantia do mínimo existencial é uma exigência fundamental para o exercício da liberdade e da democracia, deve-se ter em mente que ela ainda é insuficiente para a construção política do cidadão e da justiça. Ou seja, estão presentes na teoria de Rawls dois níveis de necessidades materiais a serem observadas: as do indivíduo como ser humano e as do indivíduo como cidadão. Rawls, ao estudar os indivíduos enquanto cidadãos, amplia o conteúdo do mínimo existencial para além das condições materiais básicas. Sua ideia de bens primários concentra-se sobre as necessidades políticas do indivíduo, enquanto cidadão.

A lista básica de bens primários, que não é um rol taxativo para Rawls e que pode ser ampliada se necessário, está dividida em cinco categorias: (1) os direitos e liberdades fundamentais; (2) a liberdade de movimento e livre escolha de ocupação num contexto de oportunidades diversificadas; (3) os poderes e prerrogativas de cargos e posições de responsabilidade nas instituições políticas e econômicas da estrutura básica; (4) a renda e a riqueza; (5) as bases sociais do autorrespeito. Esses bens, para Rawls, são coisas de que os cidadãos necessitam como pessoas livres e iguais, e exigir esses bens é uma reivindicação válida (Rawls, 2000). Importante ressaltar que o conceito de bem comum para Rawls (2008, p. 306) é de que "certas condições gerais, que num sentido apropriado, são igualmente vantajosas 
para todos" também pode ser utilizado para defender como justa uma posição de distribuição igualitária do bem ambiental.

Afinal, se um sujeito vive abaixo de um certo nível de bem-estar material e social (e acrescenta-se aqui, ambiental), ele simplesmente não pode participar da sociedade como cidadão, e muito menos como cidadão igual aos outros que detêm essas condições. Diante disso, Rawls reconhece como elemento constitucional essencial a existência de um mínimo social que supra as necessidades básicas de todos os cidadãos. Isso porque seria inócuo falar em igualdade de oportunidades e desigualdades vantajosas para os indivíduos marginalizados se eles não possuíssem sequer o básico para as suas vidas. É algo que anularia o princípio da diferença completamente, tornando-o vazio (Silva, 2015). Portanto,

considerando que muitos aspectos do que normalmente é tido como pertencente ao conteúdo do mínimo existencial estão contemplados na ideia de bens primários, sobretudo no que se refere aos pressupostos do primeiro princípio de justiça, podemos falar no mínimo existencial rawlsiano. Na medida em que insistimos no caráter político de sua concepção de justiça, podemos observar que a garantia de um mínimo existencial é um pressuposto para o bom funcionamento do Estado Democrático ou da democracia em geral. Embora possa haver, como de fato há, muita controvérsia quanto ao conteúdo do mínimo existencial, Rawls, com a ideia dos bens primários, dá importante contribuição no sentido de explicitar exigências para o efetivo exercício da autonomia e da cidadania. Nesse caso, o mínimo existencial não pode ser restringido à satisfação das necessidades físicas dos indivíduos, como se a preocupação fosse apenas com a sua sobrevivência, ou o chamado "mínimo vital". Para marcar a estreita relação com a dignidade, o mínimo existencial não pode ser atrelado apenas à satisfação das necessidades básicas materiais, mas deve visar ao desenvolvimento da pessoa como cidadã. (Weber, 2013, p. 209-210)

Rawls afirma que indivíduos em condições precárias têm sua liberdade afetada, exigindo, assim, a existência de uma garantia de direitos mínimos aos cidadãos - o que o autor denomina de bens primários sociais ou mínimo social —, ou os princípios de justiça não teriam sentido algum. Afinal, o primeiro princípio, que trata dos direitos e liberdades fundamentais, pode ser precedido de um princípio anterior que prescreva a satisfação das necessidades básicas dos cidadãos, ao menos na medida em que as satisfazer seja necessário para que eles entendam e tenham condições de exercer esses direitos e liberdades de forma efetiva. Não há dúvida de que algum princípio desse tipo tem que estar pressuposto na aplicação do primeiro princípio ${ }^{3}$ (Rawls, 2008, p. 111).

\footnotetext{
3 "A ideia principal é que o bem de uma pessoa é definido por aquilo que para ela representa o plano de vida mais racional a longo prazo, dadas circunstâncias razoavelmente favoráveis. Uma pessoa é feliz quando ela é mais ou menos bem-sucedida na realização desse plano. De forma breve, o bem é a satisfação do desejo racional" (Rawls, 2008, p. 111).
} 
Assim, como o próprio autor afirma, a definição inicial das expectativas apenas com relação a fatores como a liberdade e a riqueza é provisória, e, portanto, é necessário incluir outros tipos de bens primários, ao qual este estudo propõe o bem ambiental. Na sequência, estuda-se o modelo de um Estado Socioambiental que seja capaz de realizar a justiça ambiental, para que se realize o mínimo existencial ecológico, aquilo que Rawls propõe que as instituições façam pelo mínimo social ${ }^{4}$.

\section{CONCLUSÕES}

A proteção da dignidade da pessoa humana implica a vinculação do Estado, no sentido de que a todos os indivíduos seja assegurado um mínimo existencial material, no caso, o ecológico. Isso se traduz em condições materiais elementares, afinal é uma premissa do próprio exercício dos demais direitos, resultando, por ser fundamental para a existência humana, em uma espécie de direito a exercer os demais direitos.

4 "Uma vez definida a taxa justa de poupança ou especificada a variação apropriada das taxas, temos um critério para ajustar o nível do mínimo social. A soma de transferências e benefícios propiciados por bens públicos essenciais deve ser organizada de modo a elevar as expectativas dos menos favorecidos, de forma compatível com a poupança exigida e com a preservação das liberdades iguais. Quando a estrutura básica se apresenta nesse formato, a distribuição resultante será justa (ou, pelo menos, não será injusta), seja qual for. Cada qual recebe a renda total (salários mais transferências) a que tem direito dentro do sistema público de normas no qual se fundamentam suas expectativas legítimas" (Rawls, 2008, p. 377).
Um sujeito que não possui acesso a certas condições existenciais ecológicas mínimas não possui liberdade real e, muito menos, uma vida digna. Desse modo, o reconhecimento da garantia do mínimo existencial socioambiental representa uma condição de possibilidade para o próprio exercício dos demais direitos fundamentais, sejam eles direitos de liberdade, sejam direitos sociais ou mesmo de solidariedade. Em outras palavras, é necessária a conjugação dos direitos sociais e dos direitos ambientais para se identificarem os patamares necessários de tutela da dignidade humana, no sentido do reconhecimento de um direito-garantia do mínimo existencial socioambiental, pois esse direito sustenta o desenvolvimento de todo o potencial da vida humana, inclusive protegendo a sobrevivência da espécie humana diante da ação predatória por ela provocada.

Contudo, como foi observado, o conceito de mínimo existencial não pode ser confundido com um direito de mera sobrevivência, ou seja, como uma dimensão minimamente fisiológica, mas deve ser concebido de forma mais ampla, visto que seu fim é a proteção da vida em condições dignas. Diante disso, o conteúdo do mínimo existencial não deve ser conceituado de forma semelhante ao mínimo vital. $\mathrm{O}$ conteúdo normativo do direito ao mínimo existencial, portanto, deve ser construído com base em circunstâncias históricas e culturais concretas da comunidade estatal, tendo em vista uma perspectiva evolutiva e cumulativa dos direitos individuais e coletivos. Desse modo, as novas necessidades existenciais que surgem na dialé- 
tica das relações sociais são incorporadas ao conteúdo do mínimo existencial, uma vez que se objetiva tutelar a dignidade da pessoa humana, sendo indispensáveis para tal segurança e qualidade ambiental.

Ao que foi exposto, agrega-se a percepção de que existe, na sociedade contemporânea, uma grave injustiça na distribuição e no acesso aos recursos naturais, de modo que os indivíduos marginalizados acabam tendo não apenas os seus direitos ecológicos ameaçados, mas também comprometida a expectativa de uma vida digna. Portanto, neste trabalho, percebe-se a ligação entre o estudo de um mínimo existencial ecológico e a justiça ambiental. Esta deve reforçar a relação entre direitos e deveres ambientais, com o objetivo de redistribuir os bens naturais que assegurem um mínimo de equidade entre os indivíduos.

O direito fundamental ao ambiente apresenta, como apontam Sarlet e Fensterseifer (2014a), além de um conteúdo e uma dimensão democrática, um forte componente distributivo, de vez que a consagração do ambiente como um bem comum de todos, tal como reconhecido na Constituição Federal, harmoniza com a noção de um acesso universal e igualitário ao desfrute de uma qualidade de vida compatível com o pleno desenvolvimento da personalidade de cada pessoa humana, e considera, ainda, que tal concepção abrange os interesses das futuras gerações. Portanto, o reconhecimento do meio ambiente ecologicamente equilibrado como direito fundamental opera no sentido de agregar novos elementos normativos ao conteúdo do direito a um mínimo existencial e abre caminho para a noção de uma dimensão ecológica. Essa concepção é coerente, aliás, com o projeto político-jurídico do Estado Socioambiental.

Rawls, em sua proposta liberal, idealiza uma comunidade de cidadãos livres e iguais, capazes de exercer tais direitos de forma plena e, ao mesmo tempo, respeitar a dignidade dos demais membros da sociedade bem como de atuar politicamente na construção de um mundo mais justo. Entretanto, essa ideia não se ajusta a uma realidade em que determinados indivíduos não possuem o mínimo para uma vida digna. Os princípios de justiça, portanto, devem ser antecedidos por um princípio que determine a preservação de um mínimo existencial a cada indivíduo.

Conforme se identificou, esse mínimo não corresponde ao mínimo vital, mas ao mínimo necessário para o desenvolvimento integral do ser humano com uma vida digna. A justiça como equidade de Rawls fornece grande atenção a esse tema, pois, além de significar a preservação da dignidade, também fortalece a integração da sociedade e a manutenção de suas instituições, evitando a dominação de um grupo social sobre outro. Do mesmo modo, em Rawls, verifica-se a grande importância conferida ao Estado, pois a ele se atribui uma atuação com o intuito de impedir desigualdades excessivas.

Este trabalho, portanto, inseriu-se na discussão teórica em compreender, em termos normativos, a relação entre o mínimo 
existencial ecológico, a dimensão ecológica da dignidade da pessoa humana e a justiça em John Rawls. Reconhece-se que uma concepção ampla da dignidade da pessoa humana somada à proteção de direitos fundamentais socioambientais (no sentido de garantir um mínimo existencial socioambiental) tem importância fundamental para assegurar a vida humana livre e digna, visto que somente dentro de um meio no qual exista segurança ambiental pode se desenvolver a vida humana em toda a sua potencialidade. Além disso, só é possível realizar esse projeto (o que representa a realização da justiça ambiental) dentro de um modelo institucional favorável, qual seja, o Estado Socioambiental (Democrático e de Direito).

Estudou-se que o modelo teórico de Rawls tem o mérito de permitir a aplicação da concepção da justiça a questões diversas, ainda que o autor mesmo não tenha realizado isso a contento, como é o caso, neste artigo, da questão ambiental. Para acessar outros bens primários, que os sujeitos tanto desejam possuir, é necessário que os naturais - saúde, vigor e alegria - estejam assegurados. Além disso, o simples direito de um indivíduo a querer participar da esfera política pressupõe o acesso a esses bens naturais.

Desse modo, Rawls supõe a existência de certa escassez em qualquer sociedade; para o autor, sempre haverá uma parcela da sociedade que viverá em condições de escassez, podendo esta ser de recursos naturais ou de outros bens igualmente não disponíveis em abundância. Portanto, não é possível falar de justiça sem levar em conta as condições de escassez específicas em cada sociedade e a obrigação das instituições em assegurar permanentemente a distribuição equitativa da liberdade para se ter acesso ao bem escasso. A natureza, dentro da teoria de Rawls, pode ser considerada um "bem social ambiental natural" que deve ser preservada por si mesma, e, para todos, indistintamente, em razão de seu próprio valor, ainda que o reconhecimento deste dependa da razão. Assim, as leis devem ser aplicadas, a fim de garantir os bens naturais ambientais a todos os interessados.

Por fim, o direito ao meio ambiente ecologicamente equilibrado e sadio se agregou no rol de direitos fundamentais, pois se reconheceu sua importância para a vida de todos os sujeitos. No entanto, critica-se que a concepção fundamentada na posição rawlsiana seria demasiada antropocêntrica, porém, como visto, isso não elimina a tutela do meio ambiente, ao contrário, o meio ambiente é objeto de proteção e tutela jurídica justamente em virtude de que é condição da própria existência e da efetivação dos demais direitos humanos. O meio ambiente ecologicamente equilibrado é pressuposto para a realização dos direitos humanos e não é denegrido pelo foco teórico ser no homem racional, mas recebe proteção justamente por a vida de toda a sociedade, presente e futura, estar intimamente ligada a ele.

\section{REFERÊNCIAS}

Albuquerque, C. de. (2015). Justiça ambiental e John Rawls: aproximações possíveis. Arquivo Jurídico, 2(1), 159- 174. 
Almeida, Â. (2009). O mínimo existencial e a eficácia dos direitos fundamentais sociais nas relações entre particulares (dissertação de mestrado em Direito). Universidade de Caxias do Sul, Caxias do Sul, Brasil.

Ayala, P. de A. (2010). Mínimo existencial ecológico e transconstitucionalismo na experiência jurídica brasileira: uma primeira leitura de jurisprudência comparada. Revista de Direito Ambiental, 59, 312-332.

Baggio, R. C. (2008). Justiça Ambiental entre redistribuição e reconhecimento: a necessária democratização da proteção da natureza (tese de doutorado em Direito). Universidade Federal de Santa Catarina, Florianópolis, Brasil.

Barroso, L. R. e Mello, H. L. de. (2015). "Aqui, lá e em todo lugar": a dignidade humana no direito contemporâneo e no discurso transnacional. Doutrinas Essenciais de Direito Constitucional, 8, 33-95.

Canotilho, J. J. G. (1998). Estado de Direito. Cadernos Democráticos, 7. Fundação Mário Soares. Lisboa, Portugal: Editora Gradiva.

Felipe, S. T. (2006). Por uma questão de justiça ambiental: perspectivas críticas à teoria de John Rawls. Ethic@, 5(3), 5-31.

Fensterseifer, T. (2008). Direitos fundamentais e proteção do ambiente: a dimensão ecológica da dignidade humana no marco jurídico constitucional do estado socioambiental de direito. Porto Alegre, Brasil: Livraria do Advogado Editora.

Garcia, D. S. S. (2013). Mínimo existencial ecológico: a garantia constitucional a um patamar mínimo de qualidade ambiental para uma vida humana digna e saudável. Jurídicas, 10(1), 31-46.

Leff, E. (2009). Saber ambiental: sustentabilidade, racionalidade, complexidade, poder (Orth, L. M. E., trad.). Petrópolis, Brasil: Vozes.
Leite, J. R. M. e Ayala, P. de A. (2014). Dano ambiental: do individual ao coletivo extrapatrimonial: teoria e prática $\left(6^{\mathrm{a}}\right.$ ed.). São Paulo, Brasil: Editora Revista dos Tribunais.

Lumertz, E. S. dos S. e Vieira, F. dos S. (2012). A justiça e o direito segundo John Rawls e a questão ambiental: uma abordagem possível. Revista do Ministério Público do Rio Grande do Sul, 72, 115-139.

Martínez-Alier, J. (2007). O ecologismo dos pobres: conflitos ambientais e linguagens de valoração. São Paulo, Brasil: Contexto.

Miranda, J. P. R. de e Calça, K. G. (2014). A tutela jurídica da biodiversidade e dos conhecimentos tradicionais: uma questão de justiça equitativa entre gerações. Revista Panorâmica On-Line, 17, 40-64.

Rammê, R. S. (2012). As dimensões da justiça ambiental e suas implicações jurídicas: uma análise à luz das modernas teorias da justiça (dissertação de mestrado em Direito). Universidade de Caxias do Sul, Caxias do Sul, Brasil.

Rawls, J. (2000). O liberalismo político. São Paulo, Brasil: Editora Ática.

Rawls, J. (2008). Uma teoria da justiça (3a ed.). São Paulo, Brasil: Martins Fontes.

Rigo, M. G. (2015). Meio ambiente igualitário: análise da relação entre a justiça equitativa de Rawls e o princípio da "não-regressão" de Michel Prieur. Revista Eletrônica Direito e Política, 10(1), 220-237.

Sarlet, I. W. (2009). As dimensões da dignidade da pessoa humana: construindo uma compreensão jurídico constitucional necessária e possível. Em I. W. Sarlet (Org.), Dimensões da dignidade (pp. 15-44). Porto Alegre, Brasil: Livraria do advogado.

Sarlet, I. W. (2013). Dignidade (da pessoa) humana, mínimo existencial e justiça constitucional: 
algumas aproximações e alguns desafios. Revista do CEJUR/TJSC: Prestação Jurisdicional, 1(1), 29-44.

Sarlet, I. W. e Fensterseifer, T. (2007). Algumas notas sobre a dimensão ecológica da dignidade da pessoa humana e sobre a dignidade da vida em geral. Revista Brasileira de Direito Animal, 2(3), 69-94.

Sarlet, I. W. e Fensterseifer, T. (2010). Estado socioambiental e mínimo existencial (ecológico?): algumas aproximações. Em I. W. Sarlet (Org.), Estado socioambiental e direitos fundamentais (pp. 11-38). Porto Alegre, Brasil: Livraria do Advogado Editora.
Sarlet, I. W. e Fensterseifer, T. (2014a). Direito constitucional ambiental ( $4^{a}$ ed.). São Paulo, Brasil: Revista dos Tribunais.

Sarlet, I. W. e Fensterseifer, T. (2014b). Princípios do direito ambiental. São Paulo, Brasil: Saraiva.

Silva, L. C. da. (2015). A ideia do mínimo existencial de acordo com a teoria rawlsiana. Derecho y Cambio Social, 42, 1-27.

Weber, T. (2013). Aideia de um "mínimo existencial" de J. Rawls. Kriterion, 127, 197-210. 